\title{
Hydration and Diffusion Mechanism of Uranyl in Montmorillonite Clay: Molecular Dynamics Using an $A b$ Initio Potential.
}

Sergio Pérez-Conesa, José M. Martínez, and Enrique Sánchez Marcos*

Department of Physical Chemistry, University of Seville, 41012 Seville, Seville, Spain

\author{
E-mail: sanchez@us.es
}

Phone: +34 955421005 


\begin{abstract}
Permanent geological repositories lined with bentonite, a montmorillonite-containing clay, is one of the options considered for the storage of high level radioactive waste. If the fuel rods were dissolved by a water leak, the clay would exchange its cations by the radioactive cations slowing down its diffusion to the environment. We present an $a b$ initio force field for the uranyl-montmorillonite interaction based on the hydrated ion model, i.e. recognizing the $\left[\mathrm{UO}_{2}\left(\mathrm{H}_{2} \mathrm{O}\right)_{5}\right]^{2+}$ as the cationic species. This new interaction potential was used to run molecular dynamics simulations of the hydrated clay system. The uranyl aqua ion formed outer-sphere complexes with the clay layers in agreement with EXAFS data. The hydrate is strongly bound forming 1.4 hydrogen bonds between the first shell and clay oxygens. Uranyl-clay interaction sites were identified as groups of three $\mathrm{Mg}$ substitutions. Increasing uranyl concentration enhances mobility due to partial surface coverage. Uranyl diffuses by means of a hopping-mechanism. The constrictivity factor, $\delta_{\text {int }}$, from the simulation self-diffusion coefficient of $\left[\mathrm{UO}_{2}\right]^{2+}$ was calculated. A semiquantitative agreement with the experimental datum was obtained.
\end{abstract}

\title{
Introduction
}

Geological high-level radioactive waste repository is one of the most considered options for the permanent storage of spent nuclear fuel. The repositories are lined with natural and artificial clay materials, particularly Montmorillonite-containing clays like Bentonite. ${ }^{1,2}$ Montmorillonite is an aluminosilicate consisting of octahedral sheets of $\mathrm{AlO}_{6}$ sandwiched by sheets of $\mathrm{SiO}_{4}$ tetrahedra forming a solid layer. The layers have isomorphic substitutions of $\mathrm{Al}$ by $\mathrm{Mg}$ or $\mathrm{Si}$ by $\mathrm{Al}$ producing a net negative charge on the layers. The interlayers are filled with different amounts of aqueous solutions containing cations, such as $\mathrm{Na}^{+}$or $\mathrm{Ca}^{2+}$, compensating the layer charge. Their use as liner material is based on their cation exchange capability. If water were to breach the nuclear fuel rods and dissolve the radionucleides, the clay would exchange its interlayer cations by the radioactive cations slowing down their 
release to the environment.

Uranium is the main component of the spent nuclear fuel. At low $\mathrm{pH}$ and ionic strength its most stable form in solution is the uranyl cation, $\left[\mathrm{UO}_{2}\right]^{2+}$, in particular its pentacoordinated hydrated ion, ${ }^{3}\left[\mathrm{UO}_{2}\left(\mathrm{H}_{2} \mathrm{O}\right)_{5}\right]^{2+}(\mathrm{aq})$. EXAFS experiments infer that $\left[\mathrm{UO}_{2}\left(\mathrm{H}_{2} \mathrm{O}\right)_{5}\right]^{2+}$ confined in the montmorillonite interlayer form outer-sphere complexes. ${ }^{4}$ Apart from its intrinsic interest, the $\left[\mathrm{UO}_{2}\right]^{2+}$ cation is representative of actinyls, $\left[\mathrm{AnO}_{2}\right]^{2+}$, one of the forms adopted in nuclear fuel waste by highly-radioactive minor actinides, such as $\mathrm{Pu}, \mathrm{Np}$ and $\mathrm{Am} .{ }^{5}$

Classical molecular dynamics has proven to be a useful tool to interpret experimental information of these systems. ${ }^{1,6}$ It also provides microscopical details of the phenomena since this type of information is usually hard to obtain directly or unambiguously. Several works have been published employing MD and Monte Carlo simulations of montmorillonite-uranyl systems. Most of them study $\left[\mathrm{UO}_{2}\right]^{2+}$ at the outer surfaces of clay particles ${ }^{7-13}$ although some of them study it in the interlayer. ${ }^{14,15}$ To our knowledge none of the works compute the retardation factor $\left(R_{d}\right)$ from self-diffusion coefficient that is an important macroscopical experimental parameter to quantify the radioactive cation mobility inside the clay.

Current classical interaction potentials fitted to first-principles calculations benefit of a systematic improvement, higher robustness to extrapolation and the fact that high-level quantum mechanical calculations are becoming more affordable. ${ }^{16}$ All clay MD simulations in the literature use the original Wipff and Guilbaud empirical force field for $\left[\mathrm{UO}_{2}\right]^{2+17}$ or derived ones. Even though using this model has given many insights, ${ }^{7,10,11,14,15}$ ab initio interaction potentials for molecular cation-water and molecular cation-clay interactions could give a new and refined view of the system. Several years ago, we proposed the Hydrated Ion Model (HIM) ${ }^{18-20}$ as a method to design interaction potentials of highly-charged cations in water. The model is based on the classical electrochemical concept of the Hydrated Ion in which the species that interacts with the bulk water molecules is the cation and its first hydration shell and not the naked ion, $\mathrm{M}^{n+}-\mathrm{H}_{2} \mathrm{O}$. This model alleviates several problems of traditional $a b$ initio cation-water potentials: overestimation of the ion-first shell interaction, 
incorrect quantum mechanical dissociation limit and neglect of charge transfer to the first

shell. ${ }^{20,21}$ The approach has proven to be applicable to cations of different nature. ${ }^{19,22,23}$ Recently, we published an ab initio potential for $\left[\mathrm{UO}_{2}\right]^{2+}$ in water based on the HIM, considering the $\left[\mathrm{UO}_{2}\left(\mathrm{H}_{2} \mathrm{O}\right)_{5}\right]^{2+}$ as the central flexible species acting in solution. ${ }^{24}$ In the present work we aim to: (1) build the first ab initio $\left[\mathrm{UO}_{2}\left(\mathrm{H}_{2} \mathrm{O}\right)_{5}\right]^{2+}$-clay interaction potential based on the HIM and use it in MD simulations of $\left[\mathrm{UO}_{2}\right]^{2+}$ in confined media; (2) compute by the first time the retardation factor $\left(\delta_{\text {int }}\right)$ from MD self-diffusion coefficients; (3) interpret, at microscopical level, the aqua ion diffusion mechanism, its interaction with the clay as well as the hydration structure and dynamics of the interlayer.

\section{Methods}

\section{System definition.}

We defined our model system as a Na-montmorillonite clay, with unit formula $\mathrm{Na}_{0.66}\left[\mathrm{Al}_{3.33} \mathrm{Mg}_{0.66}\right]\left[\mathrm{Si}_{8}\right] \mathrm{O}_{20}[\mathrm{OH}]_{4} \cdot \mathrm{n}\left(\mathrm{H}_{2} \mathrm{O}\right)$. The Montmorillonite was derived from an X-ray triclinic pyrophyllite structure. ${ }^{25}$ The simulation box contains two clay layers and two interlayers. The layers of this mineral consist of a plane of $\mathrm{Al}$ or $\mathrm{Mg}$ octahedra sandwiched by $\mathrm{Si}$ tetrahedra planes, a TOT structure as is known. Each layer consists of a $9 \times 5$ supercell with random octahedral substitutions of $\mathrm{Al}^{3+}$ by $\mathrm{Mg}^{2+}$ excluding the possibility of substituting two vertex-sharing octahedra following the procedure of Holmboe. ${ }^{26}$ Relative displacements of the clay layers is prevented by fixing one $\mathrm{Al}$ atom of each clay layer.

Three monolayers of water fill the interlayer. This hydration state, known as $3 \mathrm{~W}$, corresponds to $15 \mathrm{H}_{2} \mathrm{O}$ molecules per unit cell and an interlayer spacing of $\approx 18.8 \AA .{ }^{26}$ The $3 \mathrm{~W}$ hydration state is among the most common in high level waste repositories. ${ }^{27}$ The final system box size is $\approx 47 \times 45 \times 37.6 \AA^{3}$. The system is oriented with the $z$ axis normal to the surface, such that interlayers are parallel to the $x y$ plane. $\mathrm{Na}^{+}$ions balance the negative charge of the layers. $8 \mathrm{Na}^{+}$atoms and $20 \mathrm{H}_{2} \mathrm{O}$ were substituted in each interlayer by four 
$\left[\mathrm{UO}_{2}\left(\mathrm{H}_{2} \mathrm{O}\right)_{5}\right]^{2+}$, then the simulation box contained 8 uranyl aqua ions, as displayed in Figure

1. To account for the effect of concentration, another simulation box was built with a single aqua ion per interlayer. Unless otherwise stated, all analysis will refer to the 8 uranyl system.

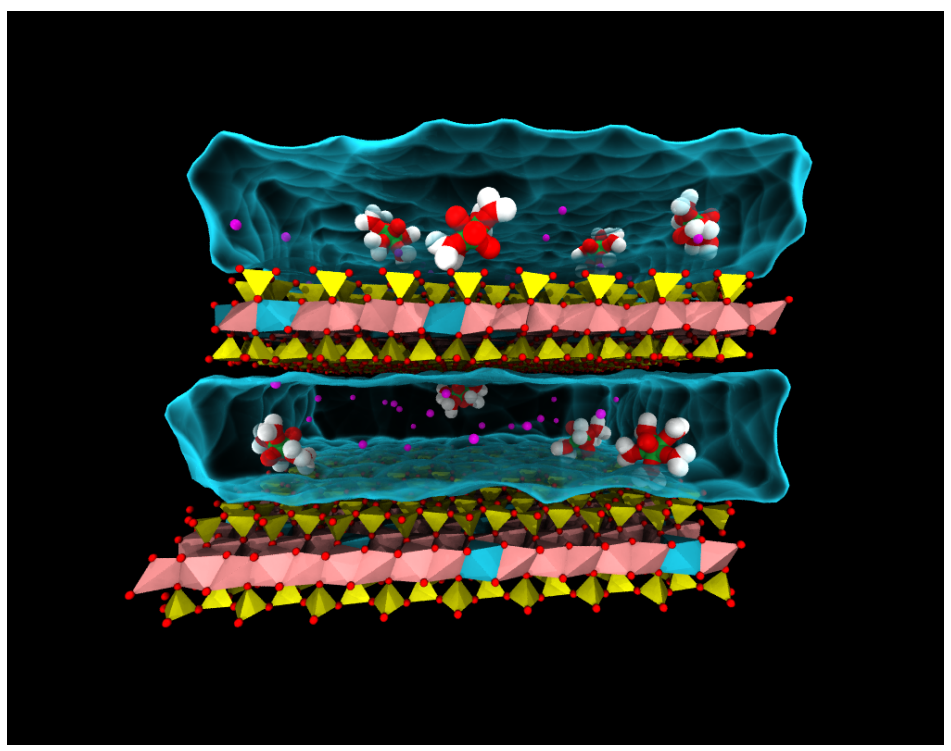

Figure 1: Simulation box. The color scheme is: $\mathrm{H}$ (white), O (red), Na (purple), MgOctahedra (blue), Al-Octahedra (pink), Si-Tetrahedra (yellow), U (green) and bulk water molecules are represented as the blue surface. Clay H atoms are omitted.

\section{Interaction Potentials}

The CLAYFF flexible force field ${ }^{28}$ was used to describe the clay. This force field assigns to each atom type a partial charge and Lennard-Jones parameters. Even though the CLAYFF was developed for SPC water, for compatibility with the hydrated ion model of $\left[\mathrm{UO}_{2}\right]^{2+}$ the TIP4P water model was used. ${ }^{29}$ The dynamics and structural properties of CLAYFF-TIP4P simulations are very similar to SPC model simulations. The $\mathrm{Na}^{+}$model of Jorgensen et al. was chosen since it was built using TIP4P water. ${ }^{30}$ Lorentz-Bertzelot combination rules were used to model the van der Waals interaction of atoms with different atom types, except those belonging to $\left[\mathrm{UO}_{2}\left(\mathrm{H}_{2} \mathrm{O}\right)_{5}\right]^{2+}$. Uranyl pentahydrate interactions with bulk $\mathrm{H}_{2} \mathrm{O}$ are described by the HIM interaction potential recently developed by our group. ${ }^{24}$ The intramolecular interactions of the uranyl pentahydrate $\left[\mathrm{UO}_{2}-\left(\mathrm{H}_{2} \mathrm{O}\right)_{5}\right]^{2+}$ are described by the Ion-Water first-shell 
potential (IW1), a site-site potential including several $r^{\text {-n }}$ terms, allowing first-shell water molecules exchanges with bulk, unlike in an harmonic bonding potential case. The finite energy barrier preventing water-release naturally appears when fitting the quantum-mechanical surface. Since first-shell $\mathrm{H}_{2} \mathrm{O}$ molecules have a different definition than bulk water, our model would not work properly if an exchange occurred during simulation. Therefore, this model is valid if water exchange time in the studied system is longer than simulation time, which is the case for $\left[\mathrm{UO}_{2}\right]^{2+}$ in water. ${ }^{31}$

\section{$\left[\mathrm{UO}_{2}\left(\mathrm{H}_{2} \mathrm{O}\right)_{5}\right]^{2+}$-Montmorillonite interaction potential, the Hydrated}

\section{Ion-Clay interaction.}

All QM calculations were carried out using $O R C A^{32}$ at the MP2 level of theory. For U, Si and $\mathrm{Al}$ atoms Stuttgart semi-relativistic pseudopotentials were used to remove respectively 60 ,

10 and 10 electrons from the core and their recommended basis sets. ${ }^{33,34}$ The rest of atoms used Dunning's cc-aug-PVDZ basis set. ${ }^{35-39}$ The RI ${ }^{40-44}$ and RIJCOSX ${ }^{45}$ scaling reduction techniques were employed to accelerate the calculations.

All system interactions can be obtained from literature except for the interaction of the hydrated ion with the clay; denoted as Hydrated Ion Clay interaction, HIC. The development of this force field is crucial to reach the goals of this study.

To model the surface we carved small molecular clusters from the two surface interaction centers. QM calculations of clay clusters interacting with uranyl have been reported in the literature. ${ }^{46,47}$ To deal with a reasonable cluster size ( $\sim 100$ atoms), they contained part of the octahedral AlO6 sheets and part of one of the tetrahedral SiO4 sheets. The cluster was carved of the crystal structure and the relative atomic positions were unchanged. Some oxygen atoms were saturated with hydrogen atoms. Our model stands on the reasonable assumption that the non-electrostatic component of the interaction is fairly local and can be approximated by a surface cluster, since the known models provide the long-range electrostatics. To obtain a set of QM structures to be fitted, unrelaxed scans were performed with 
the aqua ion in its gas phase minimum geometry. Examples of these scans are depicted in Figure 2.

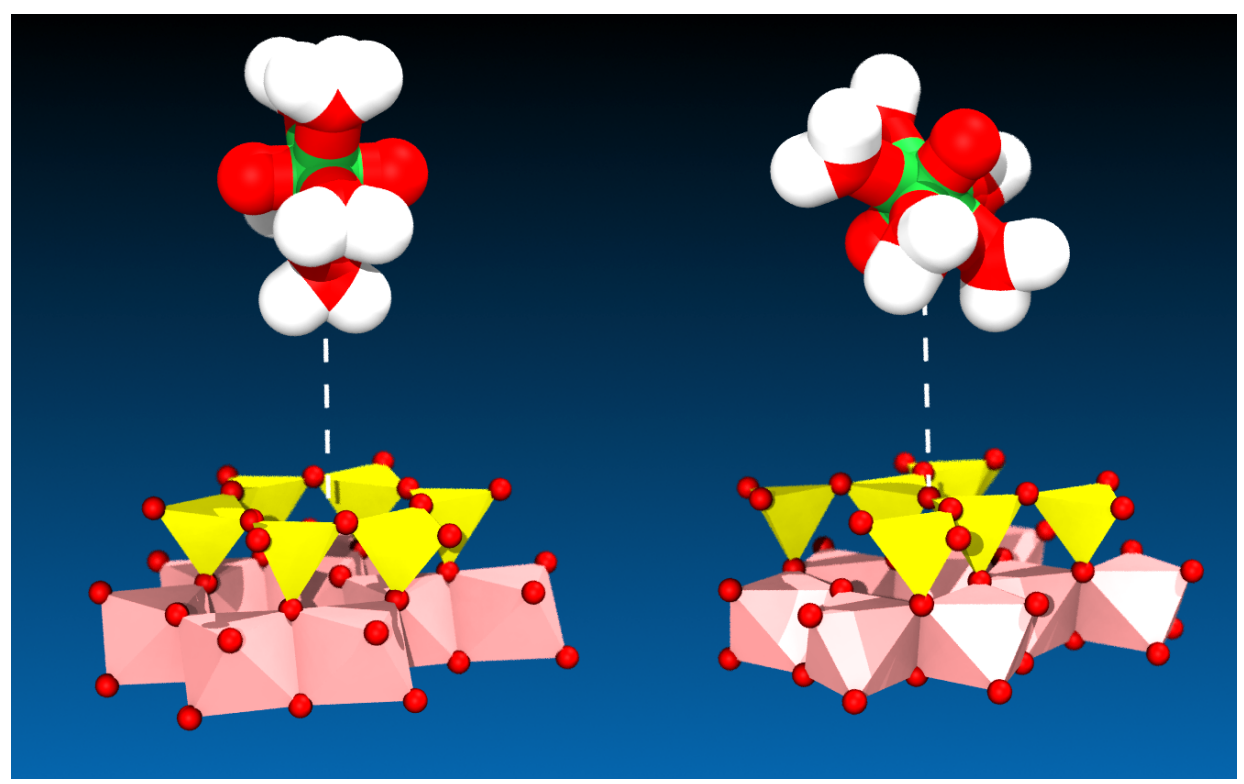

a)

b)

Figure 2: Two of the cluster-aqua ion scans used to parameterize the HIC interaction. (a) Hexagonal center scan with $90^{\circ}$ tilt angle, defined by the actinyl axis and the surface normal. (b) O-center scan with tilt angle $45^{\circ}$. Al octahedra (pink), Si tetrahedra (yellow) and $\mathrm{O}$ atoms (red), uranium atoms (green) and $\mathrm{H}$ atoms (white) are displayed. Clay $\mathrm{H}$ atoms are omitted.

The hydrated ion-clay interaction energy is defined as:

$$
E_{\text {int }}^{i}=E_{\left[\mathrm{UO}_{2}\left(\mathrm{H}_{2} \mathrm{O}\right)_{5}\right]^{2+}{ }_{- \text {clay }}}^{i}-E_{\left[\mathrm{UO}_{2}\left(\mathrm{H}_{2} \mathrm{O}\right)_{5}\right]^{2+}}-E_{\text {clay }}=E_{\text {Coul. }}^{i}+E_{\text {non-Coul. }}^{i}
$$

$E_{\text {int }}^{i}$ splits into a purely electrostatic interaction term and a non-coulomb term. We fitted only the non-coulomb interactions between $\mathrm{U}, \mathrm{O}_{\mathrm{yl}}$ (oxo bond oxygen) and $\mathrm{O}_{\mathrm{I}}$ (first-shell water molecule oxygen) atom types of the hydrated ion with the $\mathrm{O}$ and $\mathrm{O}_{\mathrm{H}}$ (hydroxyl oxygen) atom types of the clay, to which we shall refer collectively as $\mathrm{O}_{\text {clay }}$. It was necessary to include additionally a $\mathrm{O}_{\mathrm{yl}}{ }^{-} \mathrm{Si}$ term. To fit the interactions $r^{-n}$ polynomials were used. The full HIC 
functional form is presented below:

$$
\begin{aligned}
E_{\text {int }}= & E_{\text {Coul. }}^{i}+E_{\text {non-Coul. }}^{i} \\
= & \sum_{i}^{\text {aqua ion clay }} \sum_{j}^{\mathrm{U}, \mathrm{O}_{\mathrm{yl}}, \mathrm{O}_{\mathrm{I}}} \frac{q_{i} q_{j}}{r_{i j}}+\sum_{i} \sum_{j} \frac{C_{4}^{i j}}{r_{i j}^{4}}+\frac{C_{6}^{i j}}{r_{i j}^{6}}+\frac{C_{8}^{i j}}{r_{i j}^{8}}+\frac{C_{12}^{i j}}{r_{i j}^{12}} \\
& +\sum_{i}^{\mathrm{O}_{\mathrm{yl}}} \sum_{j}^{\mathrm{Si}} \frac{C_{4}^{i j}}{r_{i j}^{4}}+\frac{C_{6}^{i j}}{r_{i j}^{6}}+\frac{C_{8}^{i j}}{r_{i j}^{8}}+\frac{C_{12}^{i j}}{r_{i j}^{12}}
\end{aligned}
$$

The HIC interaction potential developed is the first ab initio force field for clay uranyl interactions. Details of the interaction potential development and the coefficients (Table S1) can be found in the Supporting Information (SI).

\section{Molecular Dynamics Simulation.}

Molecular dynamics (MD) simulations were run using $D L_{-} P O L Y_{-} C L A S S I C .{ }^{48}$ An integration time step of $1 \mathrm{fs}$ was used. The water molecules and hydroxyl groups were kept rigid using quaternion dynamics. The Ewald Sum was used to calculate the electrostatic interactions. The van der Waals interactions were truncated at a cutoff radius of $14 \AA$. The Nosé-Hoover thermostat with a target temperature of $300 \mathrm{~K}$ was applied with a characteristic time of $0.5 \mathrm{ps}$. For NPT simulations, in addition to the thermostat, the Nosé-Hoover barostat with orthorhombic constraint with a characteristic time of 0.5 ps was applied to keep the average pressure at $1 \mathrm{~atm}$. With orthorhombic constraints only the diagonal terms of the stress tensor are coupled to the barostat preserving cell shape. A total number of 9028 atoms were explicitly considered in the simulation box. The system was minimized and an NPT run to relax the simulation box was performed. 75 ns production simulation were ran for the two systems with different number of $\left[\mathrm{UO}_{2}\right]^{2+}$ aqua ions.

Uncertainties of all simulated properties are given as standard error. 


\section{Diffusion modeling.}

The translational self-diffusion coefficient, $D_{\text {interlayer }}^{M D}$, for $\left[\mathrm{UO}_{2}\right]^{2+}$ in the MD simulation was computed using the Einstein formula. ${ }^{49}$ Self-diffusion coefficients were not corrected for viscous self-coupling since Holmboe et al. ${ }^{26}$ proved its weakness in an analogous system.

Unfortunately, $D_{\text {interlayer }}^{M D}$ cannot be compared directly to the experimental diffusion parameters obtained in clay diffusion experiments. Experimentalists measure the effective diffusion coefficient, $D^{*}$ :

$$
\vec{J}=-\epsilon D^{*} \vec{\nabla} C_{U}
$$

Where $\vec{J}$ is the mass flux, $\epsilon$ is the porosity of the material (volume of pores over total volume) and $C_{U}$ is the mass concentration of uranium. Bourg and Sposito ${ }^{50}$ proposed the following model of the apparent diffusion coefficient:

$$
\epsilon \frac{D^{*}}{D_{0}}=\frac{\alpha_{\text {macropore }}+\alpha_{\text {int }} \delta_{\text {int }}}{G_{i}}
$$

Where $\alpha$ is the molar fraction in the interlayer or the macropores; $G_{i}$ is a "geometric" factor addressing tortuosity, pore irregularity and connectivity ${ }^{51} D_{0}$ is the self-diffusion coefficient of uranyl in water; and $\delta_{\text {int }}$ is a "constrictivity" factor. ${ }^{52} \delta_{\text {int }}$ is a measure of the change in diffusivity of a species in the interlayer with respect to solution. This parameter can be calculated from experiment or using self diffusion coefficients obtained from MD with the expression: ${ }^{50}$

$$
\delta_{\mathrm{int}}=\frac{D_{\mathrm{int}}^{M D}}{D_{0}^{M D}}
$$

Thus $\delta_{\text {int }}$ assesses the validity of theoretical diffusion dynamics and the microscopic conclusions predicted. In addition, $\delta_{\text {int }}^{\mathrm{H}_{2} \mathrm{O}}$ and $\delta_{\text {int }}^{\mathrm{M}^{+}}$of a clay with a given dry bulk density, $\rho_{d}$, allows numerical modelization of self-diffusion coefficient ratios over the whole range of $\rho_{d} .{ }^{50}$ 


\section{Results and Discussion}

\section{Structure of the interlayer.}

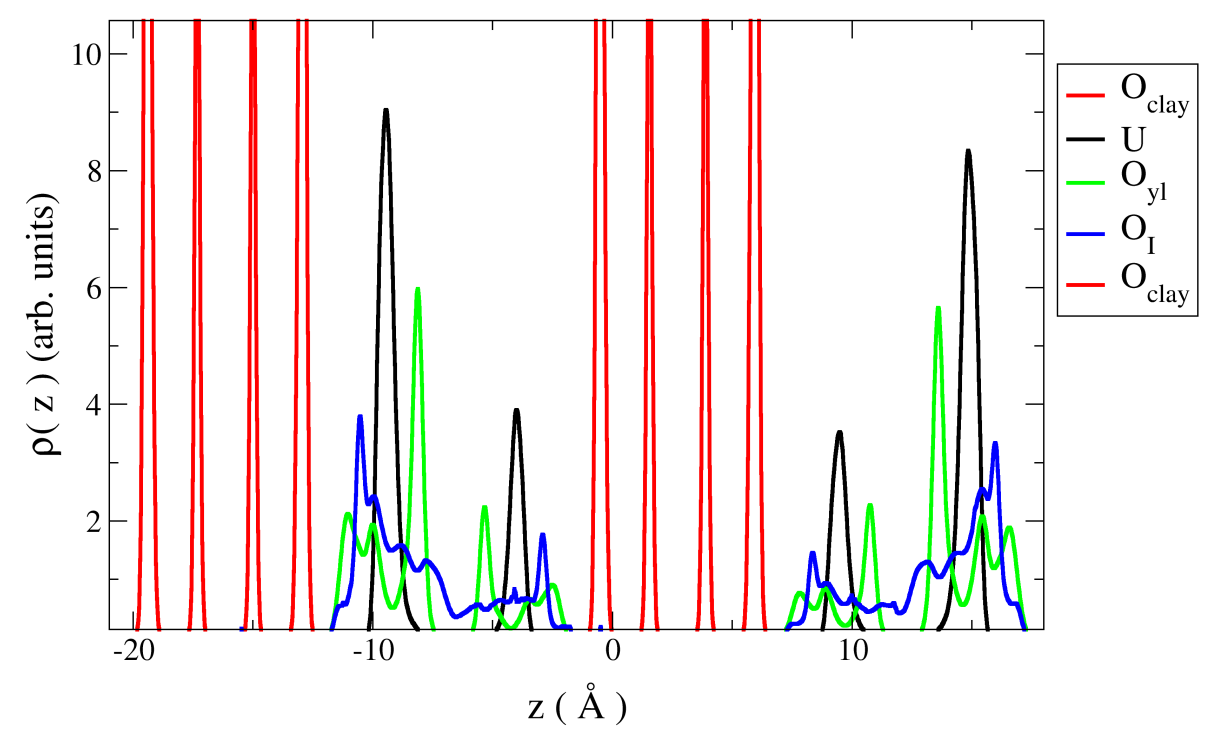

Figure 3: Z-density profile for $\left[\mathrm{UO}_{2}\right]^{2+}$-clay in the $8 \mathrm{HI}$ simulation. The red lines correspond to the $\mathrm{O}_{\text {clay }}$ atom and delimit the solid surface position.

The Z-Density profile, $\rho(z)$, of the simulation (Figure 3) shows that outer-sphere complexes are formed between the uranyl pentahydrate and the solid surface since first-shell water molecules $\left(\mathrm{O}_{\mathrm{I}}\right)$ stand between the uranyl and the clay surface. In addition, the uranyl pentahydrate entity is preserved throughout the simulation, i. e. the simulation agrees with EXAFS results, ${ }^{4}$ and with previous theoretical MD simulation studies. ${ }^{14,15}$ In the HIM description of $\left[\mathrm{UO}_{2}\left(\mathrm{H}_{2} \mathrm{O}\right)_{5}\right]^{2+}$, the first-shell molecules could leave the first-shell since these water molecules are treated as independent particles in the simulation, but they remain coordinated due to the potential energy barrier. This satisfies the requirement of our HIM model about the no-exchange of first-shell water molecules. Likewise, it shows the good behavior of the potential coupling.

The hydrated ions stay on clay surface forming outer-sphere complexes for most of the 
simulation. Only one of the uranyls travels to the other surface, although others make occasional back and forth displacements. Transition times take a few ps. The clay layer with $-0.5 \AA<z<5.8 \AA$ has 1 uranyl bound on each of its two surfaces whereas the other layer has 6. Since both layers contain the same number of substitutions, the different arrangement of the Mg substitutions in the two layers is the cause of the uranyl z-density asymmetry.

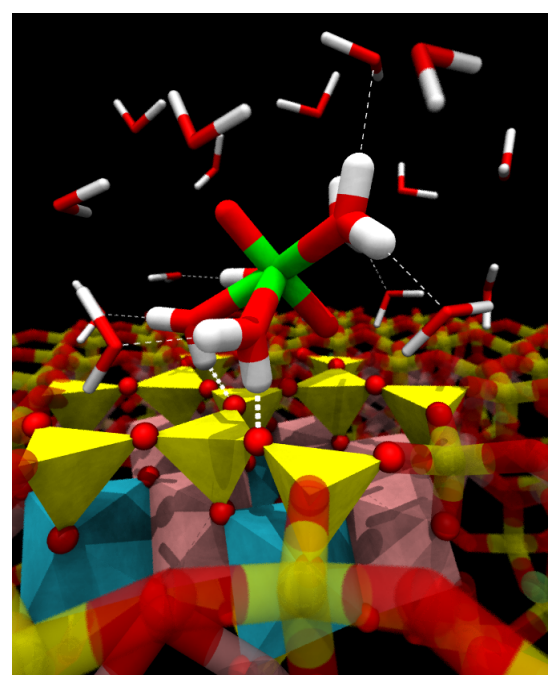

a)

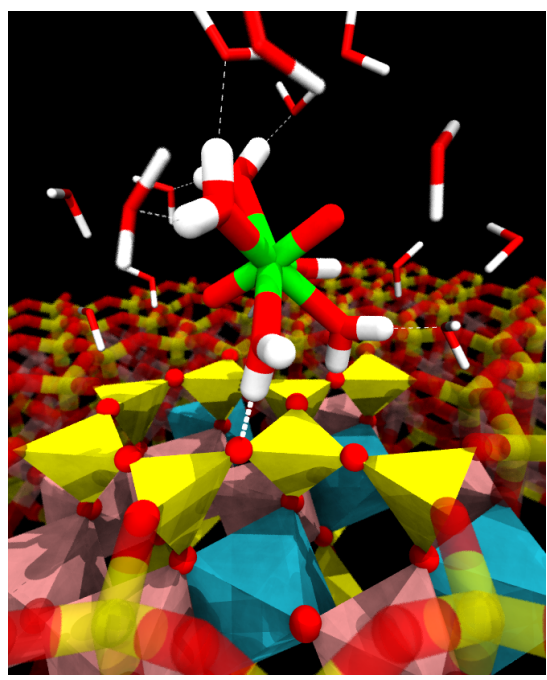

b)

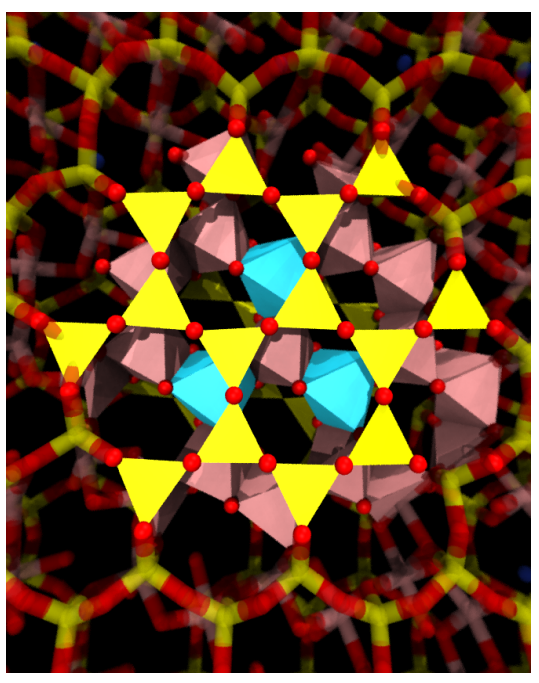

c)

Figure 4: (a)Outer-sphere HI-clay complex with a tilt angle of $\sim 35^{\circ}$ forming two H-bonds with the surface. (b)Outer-sphere HI-clay complex with a tilt angle of $\sim 60^{\circ}$ forming one $\mathrm{H}$-bond with the surface. (c)Picture of an interaction site of the clay surface. An interaction site has three $\mathrm{Mg}$ octahedra separated by only one Al octahedron. (Al octahedra (pink), $\mathrm{Mg}$ octahedra (blue), Si tetrahedra (yellow), O atoms (red), uranium atoms (green) and $\mathrm{H}$ atoms (white) are displayed. Most of the clay surface is faded and clay $\mathrm{H}$ atoms are omitted for clarity)

The $\mathrm{O}_{\mathrm{yl}} \mathrm{z}$-density shows peaks on both sides of the uranium curve because the $\mathrm{O}_{\mathrm{yl}}-\mathrm{U}-\mathrm{O}_{\mathrm{yl}}$ axis is not perpendicular to the surface. The $\mathrm{O}_{\mathrm{yl}} \mathrm{z}$-density has a split peak close to the surface. Thus, two preferential tilt angles with the surface exist. The tilt angle distribution calculated is found to be bimodal with $\sim 35^{\circ}$ and $\sim 60^{\circ}$ maxima. The first value happens when one $\mathrm{O}_{\mathrm{yl}}$ approaches an O-hexagon of the clay surface sinking in slightly and otherwise the second angle occurs. Greathouse et al. ${ }^{15}$ found tilt angles of $45^{\circ}$ in their Monte-Carlo study. We think their result is about the average of our two values if they also obtained 
a bimodal distribution. Since polarized-EXAFS experiments reveal a preferred tilt angle in between 0 and $90^{\circ},{ }^{53}$ our result is within the experimental range.

During the simulation one or two uranyl first shell water molecules form hydrogen bonds with clay surface oxygen atoms belonging to a Si tetrahedron. The average number of these HI-clay hydrogen bonds is 1.4 per uranyl and have a most likely $\mathrm{O}_{\text {clay }}-\mathrm{O}_{\mathrm{I}}$ distance of $2.37 \AA$. Figures $4 \mathrm{a}$ and $4 \mathrm{~b}$ show examples of singly and doubly H-bonded surface complexes and of the two predominant tilt angles, $\sim 35^{\circ}$ and $\sim 60^{\circ}$ respectively.

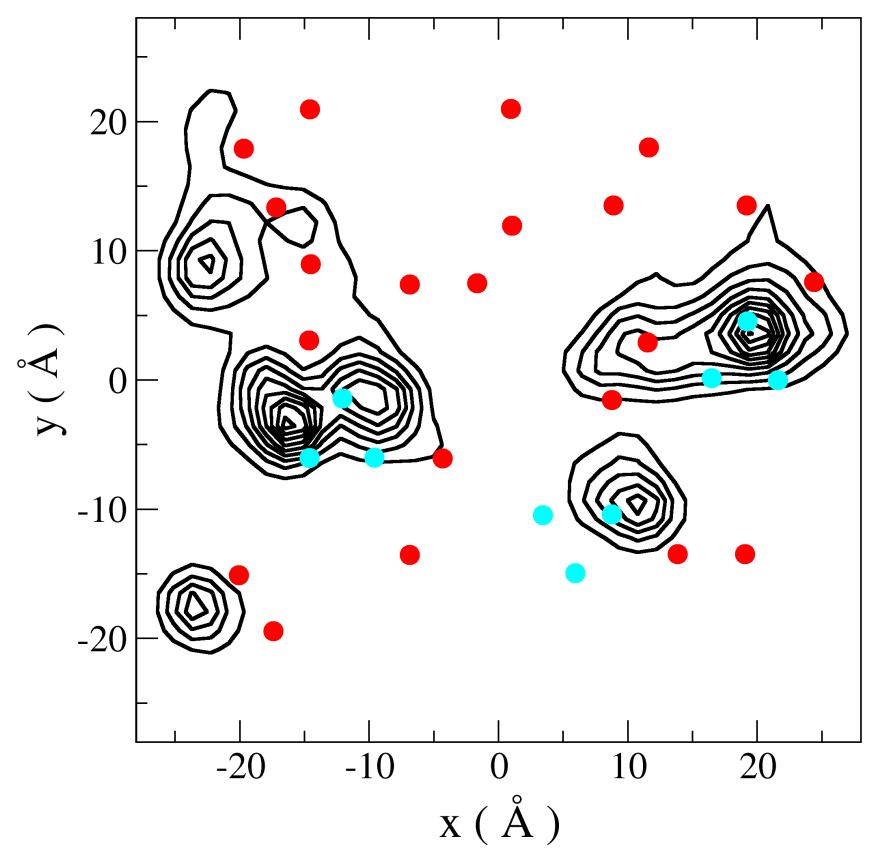

Figure 5: Probability density map of the $x y$ coordinates of the $\mathrm{U}$ atoms when they are bound to one of the clay layers on either side. Mg atoms are represented as circles: blue if they belong to an interaction site and red otherwise.

Figure 5 shows the $\mathrm{U}$ atoms probability density in the $x y$ plane when they are attached to one of the clay layers on either side. The map of the other layer can be found in the SI (Figure S2). Most of the density lies close to groups of substitutions forming triangles. We have identified this feature as an interaction site of the surface where the uranyl cations interact strongly and are retained preventing their free diffusion. Figure 4c depicts one of 
these sites. An interaction site is composed of three Mg octahedra separated by only one $\mathrm{Al}$ octahedron. This can happen if 3 substituted octahedra share a central Al octahedron or if they are located at every other vertex of a hexagonal arrangement of octahedra. Both possibilities have equivalent effects on the dynamics. By chance, the random substitution of $\mathrm{Mg}$ by $\mathrm{Al}$ when constructing our system made three interaction sites in each clay layer. Figure 6 is another piece of evidence of the strength of these sites. The radial distribution function (RDF) U-Mg (site), i.e. for $\mathrm{Mg}$ atoms belonging to an interaction site is about twice more intense than the total U-Mg RDF.

Figure 5 has smaller probability density in regions between sites. We infer from this fact a hopping (or jumping) mechanism for uranyl mobility in the clay interlayer. This mechanism involves cation oscillation around an interaction site until it detaches and rapidly moves to another site restarting the cycle. Another evidence of this mechanism is the fact that the uranyls lie on average close to a site about $70 \%$ of the time. Zaidan et al. also suggested jump-diffusion mechanism for uranyls from their MD trajectory. ${ }^{14}$

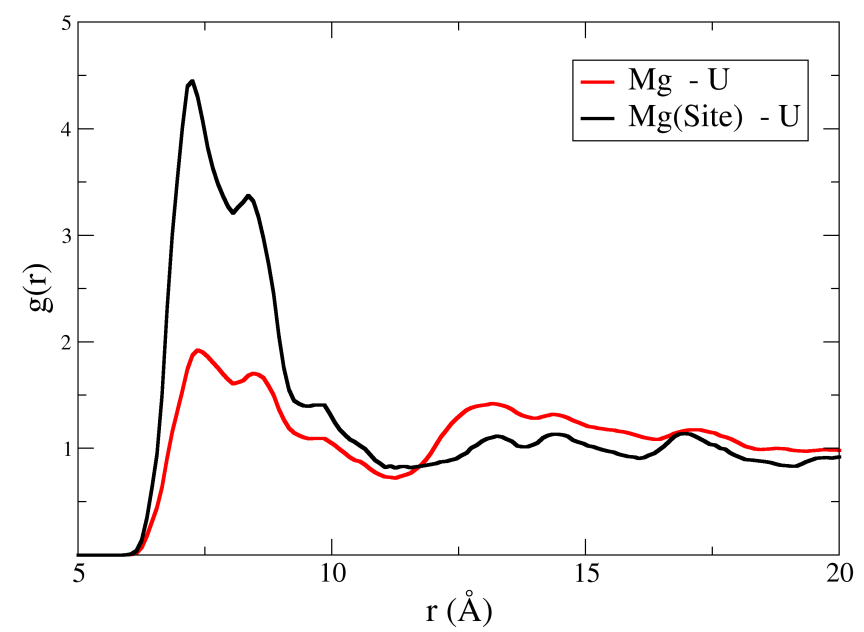

Figure 6: $\mathrm{Mg}-\mathrm{U}$ (red) and $\mathrm{Mg}_{\text {interaction site }}-\mathrm{U}$ (black) RDFs.

The electrostatic potential map of one of the four surfaces is shown in Figure 7 . The non-coulomb contribution is not provided since it is fairly flat. This map is calculated on a 
plane at the same height as the uranyl maximum of the z-density profile. The maps of the other surfaces can be found in the SI (Figure S3). The electrostatic minima differ from the interaction site positions, therefore, to understand the observed behavior other contributions must be invoked, such as the solvent competition to hydrate either the surface or the cations, cation competition for the interaction sites and the maximization of interaction distances.

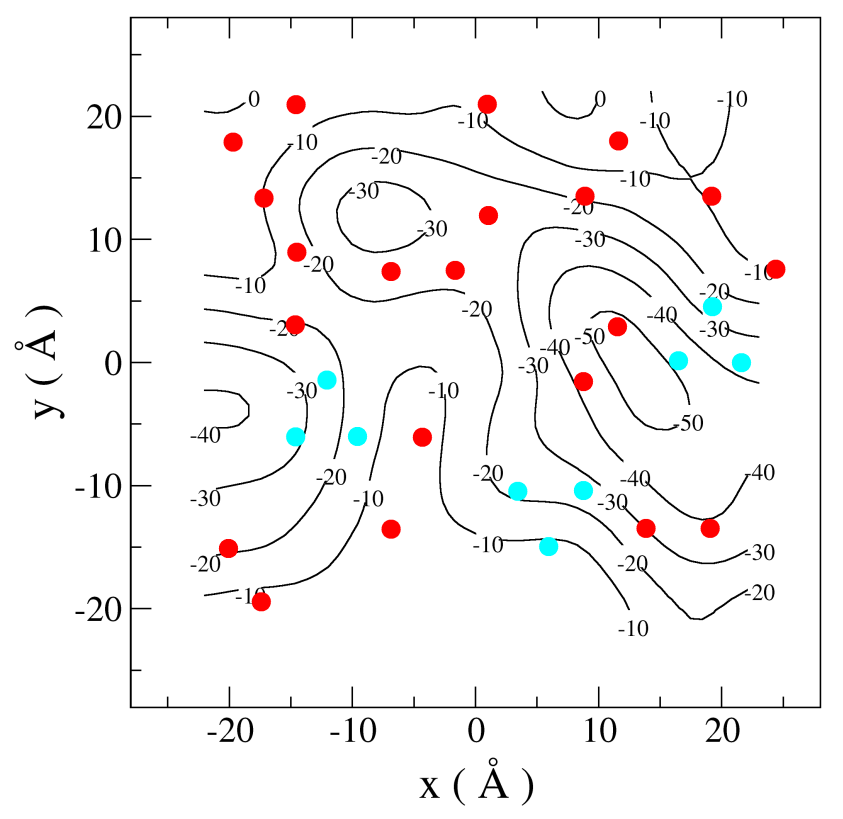

Figure 7: Contour lines of the electrostatic potential $\left(\mathrm{kcal} \mathrm{mol}^{-1} \mathrm{e}^{-1}\right)$ in the $x y$ plane with $z$ equal to $-10 \AA$. The $\mathrm{U}$ z-density profile has a maximum at this $z$ value. The maximum corresponds to uranyl being bound to the surface. $\mathrm{Mg}$ atoms are represented as circles: blue if they belong to an interaction site and red otherwise.

\section{Hydration Structure.}

The hydrated uranyl ion excludes cations within a radius of $\sim 7.5 \AA$, roughly up to its second hydration shell. This forces $\mathrm{Na}^{+}$ions to squeeze together with an average $\mathrm{Na}^{+}-\mathrm{Na}^{+}$distance of $\sim 4.4 \AA$, roughly up to its second hydration shell maximum. The sum of these volumes is $\sim 60 \%$ of the total interlayer volume if we consider the uranyl exclusion volume to be 
semi-spherical due to its attachment to the surface. The RDF of the cations contained in the interlayer with other cations is included in the SI (Figure S4).

The hydration structure of $\left[\mathrm{UO}_{2}\right]^{2+}$ in the montmorillonite resembles its hydration in solution (Figure 8). The average of $\mathrm{U}_{-} \mathrm{O}_{\mathrm{yl}}$ and $\mathrm{U}-\mathrm{O}_{\mathrm{I}}$ distances are $1.75 \AA$ and $2.45 \AA$, respectively, just like solution. ${ }^{24}$ Therefore, the first shell remains unchanged going from solution to the mineral system as experimentally observed. ${ }^{4}$ The second shell peak of the RDF in solution and in the clay differ in the intensities and coordination numbers, but not in the position. The presence of the clay creates a region around the aqua ion in which water molecules are excluded but whose volume is accounted for in the RDF normalization. This reduces the intensity of the RDF.

Since $\left[\mathrm{UO}_{2}\left(\mathrm{H}_{2} \mathrm{O}\right)_{5}\right]^{2+}$ is an anisotropical ion we will make use of the multisite cavity solute definition to compute the coordination number. ${ }^{54}$ The strategy locates spheres on solute exposed atoms with radii equal to the first minimum of the RDF of the atom and $\mathrm{O}_{\mathrm{W}}$. The coordination number is the average number of water molecules inside the volume generated by the set of interlocking spheres. The multisite solute coordination number for the pentahydrate is $16.6 \pm 0.1$ with a standard deviation between the different uranyls of 0.14 . The coordination is significantly lower than its solution value of 22 . As described earlier, one or two clay surface oxygen atoms replace two equatorial water molecules acting as second shell H-bond acceptors. Since one of the $\mathrm{O}_{\mathrm{yl}}$ atoms in the most likely orientations of the uranyl axis is close to the surface, water molecules are excluded from their solution solvation caps. These two facts result in a five water molecule loss.

The $\mathrm{Na}_{\mathrm{W}} \mathrm{O}_{\mathrm{W}}$ RFs in the clay and in solution are compared in the SI (Figure S5). Just like uranyl, the hydration structure of $\mathrm{Na}^{+}$in the mineral phase resembles its solution hydration except for a two water molecule dehydration of the second shell. The number of water molecules belonging to first or second shells of the 56 interlayer cations corresponds to $82 \%$ of the total interlayer water molecules. Since the clay layers are also charged and demand hydration, the competition within the clay for the water molecules is high, this explaining 
the second-shell partial dehydration.

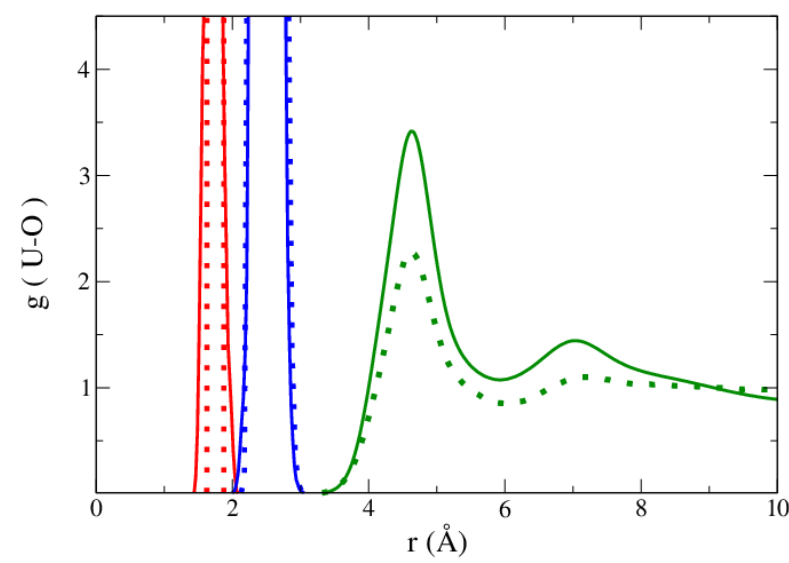

a)

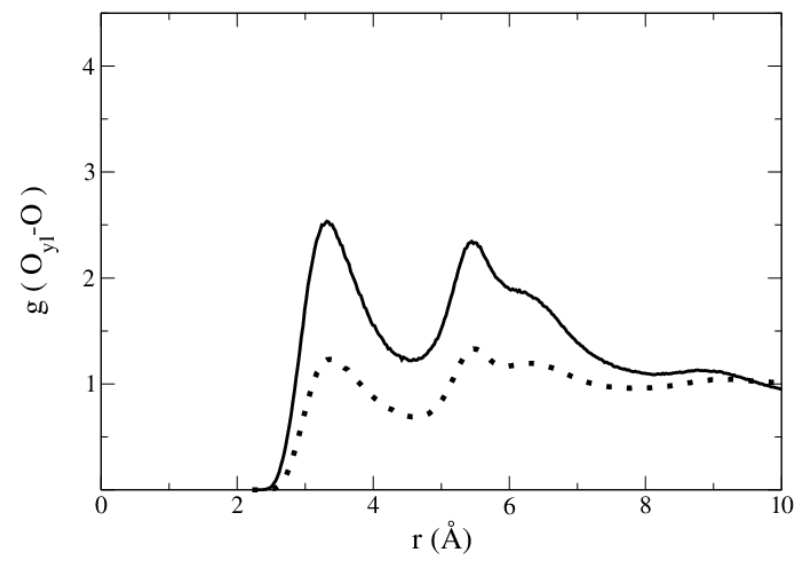

b)

Figure 8: U-O and $\mathrm{U}_{-} \mathrm{O}_{\mathrm{yl}}$ RDFs of $\left[\mathrm{UO}_{2}\left(\mathrm{H}_{2} \mathrm{O}\right)_{5}\right]^{2+}$ in the clay simulation (solid lines) and in aqueous solution ${ }^{24}$ (dotted lines): $\mathrm{U}_{-} \mathrm{O}_{\mathrm{yl}}(\mathrm{red}), \mathrm{U}-\mathrm{O}_{\mathrm{I}}$ (blue), $\mathrm{U}-\mathrm{O}_{\mathrm{W}}$ (green) and $\mathrm{O}_{\mathrm{yl}}-\mathrm{O}_{\mathrm{W}}$ (black).

\section{Uranyl diffusion modeling.}

Figure $9 \mathrm{a}$ shows the mean square displacement of each individual $\left[\mathrm{UO}_{2}\left(\mathrm{H}_{2} \mathrm{O}\right)_{5}\right]^{2+}$ and their average for the system containing 8 uranyl cations. Figure $9 \mathrm{~b}$ shows the same for the alternative system with only 2 uranyl cations. The 8HI MSDs support our hypothesis that uranyl diffusion in the interlayer occurs through a hopping mechanism. First of all, only two cations show an approximately linear profile corresponding to diffusion (the green and light blue lines). The rest span different degrees of oscillatory motion characterized by flat or oscillating MSDs. These hydrated ions are located at interaction sites oscillating around them and in rare occasions diffuse to other sites. This is why the cations have MSDs with flat oscillatory intervals combined with short linear intervals. The average MSD for the $8 \mathrm{HI}$ simulation has evident diffusive character mixed with oscillatory motion, hence the change of slope observed at $\sim 27 \mathrm{~ns}$. In any case, diffusion is strongly hindered overall if we consider 
the low values of the mean square displacements relative to the hydrated ion size $(\sim 7.5 \AA$ diameter).

Figure $9 \mathrm{~b}$ corresponds to a simulation containing a single HI per interlayer shows the lack of free diffusion ; oscillation being dominant. Figures $9 \mathrm{a}$ and $9 \mathrm{~b}$ are so different since in order to some of the cations to diffuse the interaction sites have to be at least partially occupied. This prevents free uranyl ions from attaching to them, facilitating uranyl diffusion. The surface coverage is an important factor in this system since it is determined by uranyl concentration in the interlayer solution. The observed result at low uranyl concentration (2HI) indicates the complex diffusional description of the higher concentrated sample (8HI) where the average mobility is the result of two different regimes.

The diffusion experiment of uranyl in montmorillonite that most resembles our simulation was done by Muurien. ${ }^{55}$ Bentonite MX-80 rock, whose main component is Namontmorillonite, is the absorbent material. The U-containing solutions used were artificial ground waters at a low $\mathrm{pH}$ with a significant concentration of supporting electrolytes. This

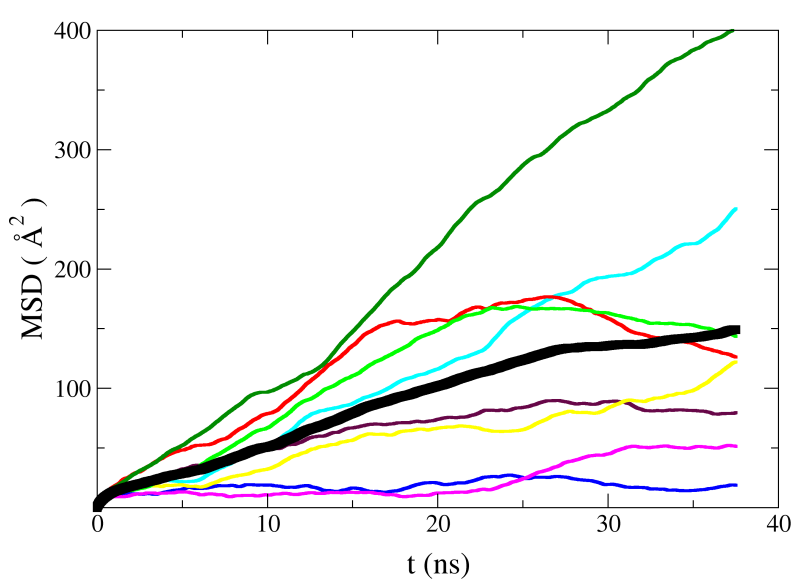

a)

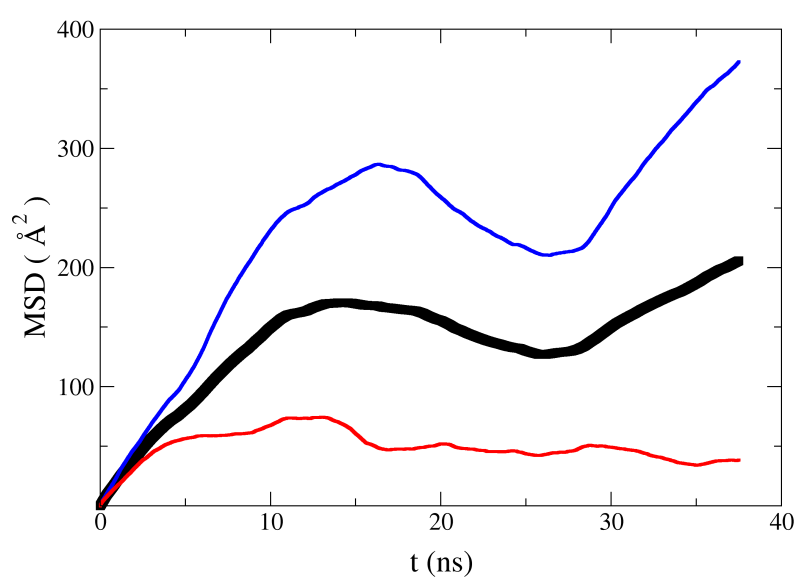

b)

Figure 9: Mean square displacements of $\left[\mathrm{UO}_{2}\left(\mathrm{H}_{2} \mathrm{O}\right)_{5}\right]^{2+}$ in the clay systems with $8 \mathrm{HI}(\mathrm{a})$ and 2HI (b). Each colored line represents an individual HI. The average MSD in the interlayer is represented by the black thick line. 
could lead to speciation or ionic strength effects not present in our simulation. However, this experimental work is chosen for comparison since it is the only one at low $\mathrm{pH}$ preventing $\left[\mathrm{UO}_{2}\left(\mathrm{H}_{2} \mathrm{O}\right)_{5}\right]^{2+}$ hydrolysis and inner-sphere coordination.

The product $\epsilon D^{*}$ depends on the clay dry bulk density, $\rho_{d}$. Thus, we have interpolated $\epsilon D^{*}$ to the simulation dry bulk density $\left(\rho_{d}=1.4 \mathrm{~g} \mathrm{~cm}^{-3}\right.$ ) as done by Moore et al ${ }^{2}$ (details are given in the SI). Unfortunately, the level of partition of uranyl in the clay between the interlayers of Montmorillonite microcrystals and the material macropores is unknown. Therefore to use Equation 4 we must assume that the interlayers contain most of the uranyl. In that case the molar fractions of uranyl in the macropores and interlayers would be: $\alpha_{\text {macropore }} \approx 0$ and $\alpha_{\text {interlayer }} \approx 1$. This is reasonable for compacted clays and has been done by Holmboe and Bourg. ${ }^{26} G_{i}$ for water saturated Na-Montmorillonite is $4.0 \pm 1.6 .{ }^{56}$ We interpolated $\delta_{\text {int }}^{\text {exp }} \approx 0.61 \cdot 10^{-3}$ for $\rho_{d}=1.4 \mathrm{~g} \mathrm{~cm}^{-3}$.

In the simulation we obtain $D^{\mathrm{MD}}=(0.009 \pm 0.004) 10^{-5} \mathrm{~cm}^{2} \mathrm{~s}^{-1}$ for uranyl, splitting the simulation into two independent blocks and averaging over them. We obtain a $\delta_{\text {int }}=3.6 \cdot 10^{-3}$. Despite the complexity of the experimental system, our predicted constrictivity factor is one order of magnitude larger than the experimental value. This relative agreement seems to indicate that our modelization has captured part of the key features in this complex system. There are three main causes of discrepancy between our value and the experiment: the limitations of our clay model, the difference in interlayer composition, and the lack of statistics due to the long time scale of the jumps.

The great advantage of this theoretical estimation of diffusion parameters is the detailed microscopical knowledge obtained. MD predictions allows checking if the system modelization is consistent with experimental evidence and supplies knowledge unreachable from experiment. To the best of our knowledge, it is first time $\delta_{\text {int }}$ of uranyl in clays has been computed from MD simulations.

Apart from the attraction of uranyl to interaction sites, the crowding of $\mathrm{Na}^{+}$and $\left[\mathrm{UO}_{2}\left(\mathrm{H}_{2} \mathrm{O}\right)_{5}\right]^{2+}$ cations in the interlayer could be a reducing factor of uranyl mobility. To 
study this an analogous $8 \mathrm{HI}$ simulation was run but without $\mathrm{Na}^{+}$and the MSD profile seems to be unaffected by the presence of the Na. The mean square displacement can be found in the SI (Figure S6). Interestingly, $D_{\mathrm{Na}}^{\mathrm{MD}}=0.4 \cdot 10^{-5} \mathrm{~cm}^{2} \mathrm{~s}^{-1}$ in the $8 \mathrm{HI}$ simulation and $D_{\mathrm{Na}}^{\mathrm{MD}}=0.7 \cdot 10^{-5} \mathrm{~cm}^{2} \mathrm{~s}^{-1}$ if no uranyl is present. Therefore, uranyl affects strongly sodium diffusion but not on the contrary. This can be simply explained by the fact that although their interaction is equal and opposite, the uranyl hydrated ion is an order of magnitude heavier and also that uranyl has stronger interaction with the clay. Thus, $\left[\mathrm{UO}_{2}\left(\mathrm{H}_{2} \mathrm{O}\right)_{5}\right]^{2+}$ moves pushing sodium out of their path and $\mathrm{Na}^{+}$must divert the $\left[\mathrm{UO}_{2}\left(\mathrm{H}_{2} \mathrm{O}\right)_{5}\right]^{2+}$ sign-posts to move.

\section{Conclusions}

We have successfully developed the first ab initio interaction potential between montmorillonite clay and uranyl based on the Hydrated Ion Model. The classical MD simulation of $\left[\mathrm{UO}_{2}\right]^{2+}$ in clay shows that outer-sphere complexes appear in the simulation as inferred from EXAFS data. ${ }^{4}$ The aqua ions adsorb strongly with the $\left[\mathrm{UO}_{2}\right]^{2+}$ molecular axis at the preferred tilt angles of $\sim 35^{\circ}$ and $\sim 60^{\circ}$. The complex binds to the surface forming on average 1.4 hydrogen bonds between first-shell water molecules and surface oxygen atoms. The second hydration shell of uranyl is dehydrated in five water molecules with respect to solution, due to the adsorption phenomena on the clay surface. The constrictivity factor of uranyl was computed from simulation. For this type of systems, to the best of our knowledge, it is the first time this has been done. The theoretical constrictivity factor overestimates by a factor of six the experimental value. This partial disagreement might be, in part, due to differences between the experimental conditions and those of the simulation. The clay has interaction sites formed by three close Mg octahedra. These sites are occupied by uranyl during most of

the simulation time. Due to the interaction with the sites, $\left[\mathrm{UO}_{2}\left(\mathrm{H}_{2} \mathrm{O}\right)_{5}\right]^{2+}$ diffusion happens through hopping mechanism. In order for some of the uranyl to have a proper diffusive mo- 
tion, a partial surface site coverage must exist. Therefore, a concentration threshold must be reached in order uranyl diffusion to occur. The interaction sites described in this work could become a new design parameter of Montmorillonite based liner materials for high level radioactive waste facilities in order to maximize their retention capacity.

\section{Acknowledgement}

We thank Dr. Rafael R. Pappalardo for useful comments and computational support. This work was financially supported by Junta de Andalucía of Spain (Proyecto de Excelencia P11-FQM7607). Sergio Pérez-Conesa thanks the Spanish Ministry of Education, Culture and Sports for a PhD grant FPU (FPU14/02100).

\section{Supporting Information Available}

Details of the interaction potential design, parameters and fit quality; details of the interpolation of the constrictivity factor; the U-probability density of the other interlayer; additional

electrostatic potential maps; the cation-cation RDFs ; the comparison of the $\mathrm{Na}^{-\mathrm{O}_{\mathrm{W}}} \mathrm{RDFs}$ for the clay and solution systems and the MSD of uranyl in a sodiumless clay simulation. This material is available free of charge via the Internet at http://pubs.acs.org/.

\section{References}

(1) Miller, A. W.; Wang, Y. Radionuclide Interaction with Clays in Dilute and Heavily Compacted Systems: A Critical Review. Environ. Sci. Technol. 2012, 46, 1981-1994.

(2) Moore, S. M.; Shackelford, C. D. Uranium Diffusion in Soils and Rocks. 2011; Proceedings Tailings and Mine Waste 2011, pp. 549-561, (2011).

(3) Gutowski, K. E.; Dixon, D. A. Predicting the Energy of the Water Exchange Reaction 
and Free Energy of Solvation for the Uranyl Ion in Aqueous Solution. J. Phys. Chem. A 2006, 110, 8840-8856.

(4) Catalano, J. G.; Brown, G. E., Jr. Uranyl Adsorption onto Montmorillonite: Evaluation of Binding Sites and Carbonate Complexation. Geochim. Cosmochim. Acta 2005, 69, 2995-3005.

(5) Morimoto, K.; Kato, M.; Uno, H.; Hanari, A.; Tamura, T.; Sugata, H.; Sunaoshi, T.; Kono, S. Preparation and Characterization of $(\mathrm{Pu}, \mathrm{U}, \mathrm{Np}, \mathrm{Am}$, Simulated $\mathrm{FP}) \mathrm{O}_{2-x} . J$. Phys. Chem. Solids 2005, 66, 634-638.

(6) Greathouse, J. A.; Refson, K.; Sposito, G. Molecular Dynamics Simulation of Water Mobility in Magnesium-smectite Hydrates. J. Am. Chem. Soc. 2000, 122, 11459-11464.

(7) Zhang, N.; Liu, X.; Li, C.; Liu, C. Effect of Electrolyte Concentration on Uranium Species Adsorption: A Molecular Dynamics Study. Inorg. Chem. Front. 2015, 2, 6774 .

(8) Greathouse, J. A.; Cygan, R. T. Molecular Dynamics Simulation of Uranyl (VI) Adsorption Equilibria onto an External Montmorillonite Surface. Phys. Chem. Chem. Phys. 2005, 7, 3580-3586.

(9) Liu, X.-y.; Wang, L.-h.; Zheng, Z.; Kang, M.-l.; Li, C.; Liu, C.-l. Molecular Dynamics Simulation of the Diffusion of Uranium Species in Clay Pores. J. Hazard. Mater. 2013, 244, 21-28.

(10) Marry, V.; Rotenberg, B.; Turq, P. Structure and Dynamics of Water at a Clay Surface from Molecular Dynamics Simulation. Phys. Chem. Chem. Phys. 2008, 10, 4802-4813.

(11) Teich-McGoldrick, S. L.; Greathouse, J. A.; Cygan, R. T. Molecular Dynamics Simulations of Uranyl Adsorption and Structure on the Basal Surface of Muscovite. Mol. Simul. 2014, 40, 610-617. 
(12) Yang, W.; Zaoui, A. Behind Adhesion of Uranyl onto Montmorillonite Surface: A Molecular Dynamics Study. J. Hazard. Mater. 2013, 261, 224-234.

(13) Greathouse, J. A.; Cygan, R. T. Water Structure and Aqueous Uranyl (VI) Adsorption Equilibria onto External Surfaces of Beidellite, Montmorillonite, and Pyrophyllite: Results from Molecular Simulations. Environ. Sci. Technol. 2006, 40, 3865-3871.

(14) Zaidan, O. F.; Greathouse, J. A.; Pabalan, R. T. Monte Carlo and Molecular Dynamics Simulation of Uranyl Adsorption on Montmorillonite Clay. Clays Clay Miner. 2003, 51, $372-381$.

(15) Greathouse, J. A.; Stellalevinsohn, H. R.; Denecke, M. A.; Bauer, A.; Pabalan, R. T. Uranyl Surface Complexes in a Mixed-charge Montmorillonite: Monte Carlo Computer Simulation and Polarized XAFS Results. Clays Clay Miner. 2005, 53, 278-286.

(16) Stone, A. The Theory of Intermolecular Forces, 2nd ed.; Oxford University Press: Oxford, 2013.

(17) Guilbaud, P.; Wipff, G. Hydration of Uranyl $\left(\mathrm{UO}_{2}^{2+}\right)$ Cation and Its Nitrate Ion and 18crown-6 Adducts Studied by Molecular Dynamics Simulations. J. Phys. Chem. 1993, 97, 5685-5692.

(18) Pappalardo, R. R.; Martínez, J. M.; Sánchez Marcos, E. Application of the Hydrated Ion Concept for Modeling Aqueous Solutions Containing Highly Charged Ions: A Monte Carlo Simulation of $\mathrm{Cr}^{3+}$ in Water Using an Ab Initio Intermolecular Potential. J. Phys. Chem. 1996, 100, 11748-11754.

(19) Pappalardo, R. R.; Sánchez Marcos, E. Recovering the Concept of the Hydrated Ion for Modeling Ionic Solutions: A Monte Carlo Study of Zinc(2+) in Water. J. Phys. Chem. 1993, 97, 4500-4504. 
(20) Martínez, J. M.; Pappalardo, R. R.; Sánchez Marcos, E. First-principles Ion-water Interaction Potentials for Highly Charged Monatomic Cations. Computer Simulations of $\mathrm{Al}^{3+}, \mathrm{Mg}^{2+}$, and $\mathrm{Be}^{2+}$ in Water. J. Am. Chem. Soc. 1999, 121, 3175-3184.

(21) Sánchez Marcos, E.; Pappalardo, R. R.; Barthelat, J. C.; Xavier Gadea, F. Theoretical Suggestion for the Aquazinc(2+) Formation. J. Phys. Chem. 1992, 96, 516-518.

(22) Galbis, E.; Hernández-Cobos, J.; den Auwer, C.; Le Naour, C.; Guillaumont, D.; Simoni, E.; Pappalardo, R. R.; Sánchez Marcos, E. Solving the Hydration Structure of the Heaviest Actinide Aqua Ion Known: The Californium (III) Case. Angew. Chem. Int. Ed. English 2010, 122, 3899-3903.

(23) Martínez, J. M.; Torrico, F.; Pappalardo, R. R.; Sánchez Marcos, E. Understanding the Hydration Structure of Square-planar Aquaions: The $\left[\mathrm{Pd}\left(\mathrm{H}_{2} \mathrm{O}\right)_{4}\right]^{2+}$ Case. J. Phys. Chem. B 2004, 108, 15851-15855.

(24) Pérez-Conesa, S.; Torrico, F.; Martínez, J. M.; Pappalardo, R. R.; Sánchez Marcos, E. A Hydrated Ion Model of $\left[\mathrm{UO}_{2}\right]^{2+}$ in Water: Structure, Dynamics, and Spectroscopy from Classical Molecular Dynamics. J. Chem. Phys. 2016, 145, 224502.

(25) Bickmore, B. R.; Rosso, K. M.; Nagy, K. L.; Cygan, R. T.; Tadanier, C. J. Ab Initio Determination of Edge Surface Structures for Dioctahedral 2: 1 Phyllosilicates: Implications for Acid-base Reactivity. Clays Clay Miner. 2003, 51, 359-371.

(26) Holmboe, M.; Bourg, I. C. Molecular Dynamics Simulations of Water and Sodium Diffusion in Smectite Interlayer Nanopores As a Function of Pore Size and Temperature. J. Phys. Chem.C 2014, 118, 1001-1013.

(27) Holmboe, M.; Wold, S.; Jonsson, M. Porosity Investigation of Compacted Bentonite Using XRD Profile Modeling. J. Contam. Hydrol. 2012, 128, 19-32. 
(28) Cygan, R. T.; Liang, J.-J.; Kalinichev, A. G. Molecular Models of Hydroxide, Oxyhydroxide, and Clay Phases and the Development of a General Force Field. J. Phys. Chem. B 2004, 108, 1255-1266.

(29) Jorgensen, W. L.; Chandrasekhar, J.; Madura, J. D.; Impey, R. W.; Klein, M. L. Comparison of Simple Potential Functions for Simulating Liquid Water. J. Chem. Phys. 1983, 79, 926-935.

(30) Jensen, K. P.; Jorgensen, W. L. Halide, Ammonium, and Alkali Metal Ion Parameters for Modeling Aqueous Solutions. J. Chem. Theory Comput. 2006, 2, 1499-1509.

(31) Helm, L.; Merbach, A. E. Inorganic and Bioinorganic Solvent Exchange Mechanisms. Chem. Rev. 2005, 105, 1923-1960.

(32) Neese, F. The Orca Program System. Wiley Interdiscip. Rev. Comput. Mol. Sci. 2012, 2, 73-78.

(33) Cao, X.; Dolg, M. Segmented Contraction Scheme for Small-core Actinide Pseudopotential Basis Sets. J. Mol. Struct. THEOCHEM 2004, 673, 203-209.

(34) Weigend, F.; Ahlrichs, R. Balanced Basis Sets of Split Valence, Triple Zeta Valence and Quadruple Zeta Valence Quality for H to Rn: Design and Assessment of Accuracy. Phys. Chem. Chem. Phys. 2005, 7, 3297-3305.

(35) Dunning Jr., T. H. Gaussian Basis Sets for Use in Correlated Molecular Calculations. I. the Atoms Boron through Neon and Hydrogen. J. Chem. Phys. 1989, 90, 1007-1023.

(36) Woon, D. E.; Dunning Jr., T. H. Gaussian Basis Sets for Use in Correlated Molecular Calculations. Iv. Calculation of Static Electrical Response Properties. J. Chem. Phys. 1994, 100, 2975-2988.

(37) Woon, D. E.; Dunning Jr., T. H. Gaussian Basis Sets for Use in Correlated Molecular 
Calculations. III. the Atoms Aluminum through Argon. J. Chem. Phys. 1993, 98, $1358-1371$.

(38) Kendall, R. A.; Harrison, R. J.; Dunning Jr., T. H.; Harrison, R. J. Electron Affinities of the First-row Atoms Revisited. Systematic Basis Sets and Wave Functions. J. Chem. Phys. 1992, 96, 6796-6806.

(39) Wilson, A. K.; van Mourik, T.; Dunning Jr., T. H. Gaussian Basis Sets for Use in Correlated Molecular Calculations. VI. Sextuple Zeta Correlation Consistent Basis Sets for Boron through Neon. J. Mol. Struct. THEOCHEM 1996, 388, 339-349.

(40) Dunlap, B. I.; Connolly, J. W. D.; Sabin, J. R. On Some Approximations in Applications of $\mathrm{X}_{\alpha}$ Theory. J. Chem. Phys.. 1979, 71, 3396-3402.

(41) Van Alsenoy, C. Ab Initio Calculations on Large Molecules: The Multiplicative Integral Approximation. J. Comp. Chem. 1988, 9, 620-626.

(42) Kendall, R. A.; Früchtl, H. A. The Impact of the Resolution of the Identity Approximate Integral Method on Modern Ab Initio Algorithm Development. Theor. Chem. Acc. 1997, 97, 158-163.

(43) Eichkorn, K.; Treutler, O.; Öhm, H.; Häser, M.; Ahlrichs, R. Auxiliary Basis Sets to Approximate Coulomb Potentials. Chem. Phys. Lett. 1995, 240, 283-290.

(44) Eichkorn, K.; Weigend, F.; Treutler, O.; Ahlrichs, R. Auxiliary Basis Sets for Main Row Atoms and Transition Metals and Their Use to Approximate Coulomb Potentials. Theor. Chem. Acc. 1997, 97, 119-124.

(45) Neese, F.; Wennmohs, F.; Hansen, A.; Becker, U. Efficient, Approximate and Parallel Hartree-fock and Hybrid DFT Calculations. a "chain-of-spheres" Algorithm for the Hartree-fock Exchange. Chem. Phys. 2009, 356, 98-109. 
(46) Tunega, D.; Haberhauer, G.; Gerzabek, M. H.; Lischka, H. Theoretical Study of Adsorption Sites on the (001) Surfaces of 1:1 Clay Minerals. Langmuir 2002, 18, 139-147.

(47) Tunega, D.; Benco, L.; Haberhauer, G.; Gerzabek, M. H.; Lischka, H. Ab Initio Molecular Dynamics Study of Adsorption Sites on the (001) Surfaces of 1:1 Dioctahedral Clay Minerals. J. Phys. Chem. B 2002, 106, 11515-11525.

(48) Todorov, I. T.; Smith, W.; Trachenko, K.; Dove, M. T. DL_POLY_3: New Dimensions in Molecular Dynamics Simulations Via Massive Parallelism. J. Mat. Chem. 2006, 16, 1911-1918.

(49) Frenkel, D.; Smit, B. Understanding Molecular Simulation. from Algorithms to Applications, 2nd ed.; Academic Press: San Diego,USA, 2002.

(50) Bourg, I. C.; Sposito, G. Connecting the Molecular Scale to the Continuum Scale for Diffusion Processes in Smectite-rich Porous Media. Environ. Sci. Technol. 2010, 44, 2085-2091.

(51) Dykhuizen, R. C.; Casey, W. H. An Analysis of Solute Diffusion in Rocks. Geochim. Cosmochim. Acta 1989, 53, 2797-2805.

(52) Grathwohl, P. Diffusion in Natural Porous Media: Contaminant Transport, Sorption/desorption and Dissolution Kinetics; Springer Science \& Business Media: New York, 1997.

(53) Denecke, M. A.; Bauer, A.; Kim, J. I.; Moll, H. Polarization Dependent XANES of Uranium (VI) Sorbed onto Smectite. Miner. Interact. Close to Equilib. 1999, 35-37.

(54) Melchior, A.; Martínez, J. M.; Pappalardo, R. R.; Sánchez Marcos, E. Hydration of Cisplatin Studied by an Effective Ab Initio Pair Potential Including Solute-Solvent Polarization. J. Chem. Theory Comput. 2013, 9, 4562-4573. 
(55) Muurinen, A. Diffusion of Uranium in Compacted Sodium Bentonite. Eng. Geol. 1990, 28, 359-367.

(56) Bourg, I. C.; Sposito, G.; Bourg, A. Tracer Diffusion in Compacted, Water-saturated Bentonite. Clays Clay Miner. 2006, 54, 363-374. 
Graphical TOC Entry

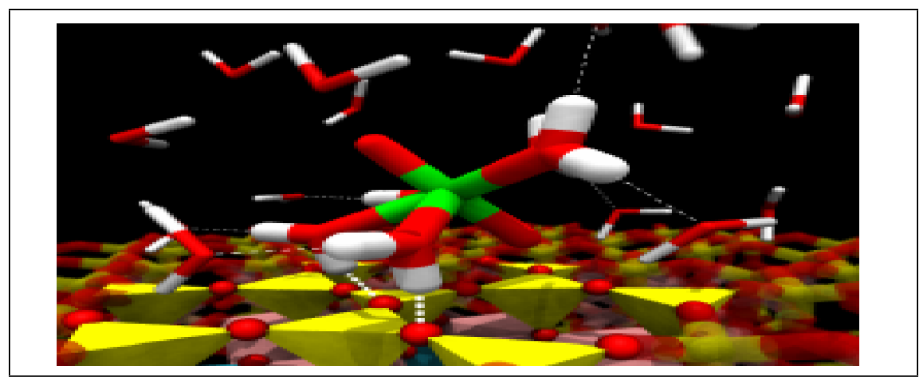

